\title{
Study on the Effects of Sewage Irrigation on Soil
}

\author{
Xiuli $\mathrm{Li}^{*}$ and $\mathrm{Xu} \mathrm{Wu} \mathrm{u}^{* *(* * *) \dagger}$ \\ *School of Water Conservancy, North China University of Water Resources and Electric Power, Zhengzhou, 450045, \\ China \\ **School of Water Conservancy and Hydroelectric Power, Hebei University of Engineering, Handan, 056038, China \\ ***Hydrology and Water Resources Survey Bureau of Handan Hebei Province, Handan, 056001, China \\ †Corresponding author: Xu Wu; 466199307@qq.com
}

Nat. Env. \& Poll. Tech. Website: www.neptjournal.com

Received: 21-01-2020

Revised: 15-02-2020

Accepted: 16-04-2020

Key Words:

Sewage irrigation

Soil

Heavy metals

Potential ecological risk

Evaluation analysis

\begin{abstract}
The long-term use of sewage to irrigate farmland will increase the content of heavy metals in the soil and cause soil pollution. Heavy metal pollution in soils will restrict the sustainable development of local agriculture and will have a negative impact on the ecological environment. In this paper, the irrigation areas using domestic sewage, mixed sewage and industrial sewage as an irrigation water source for many years have been selected as the research objects, and the content of the heavy metals lead $(\mathrm{Pb})$, copper $(\mathrm{Cu})$, zinc $(\mathrm{Zn})$ and cadmium $(\mathrm{Cd})$ in the soil with the depth of $0-20 \mathrm{~cm}, 20-50 \mathrm{~cm}$ and $50-80 \mathrm{~cm}$ of three kinds of sewage irrigation areas are assessed using single factor pollution index method and Nemerow comprehensive index method, and the potential ecological risks of heavy metals in the soil are assessed using Hakanson ecological risk index method. The results show that the content of heavy metals $\mathrm{Pb}, \mathrm{Cu}, \mathrm{Zn}$ and $\mathrm{Cd}$ in different depths of the three sewage irrigation areas does not exceed the national standard limit, and the heavy metal pollution grade in the soil belongs to the safety grade, indicating that the content of heavy metals in the soil has not reached the alert level. The potential ecological risks of heavy metals in the soil show minor ecological risks judging from single indexes, while $\mathrm{Cd}$ shows that the ecological risks are at a strong level. Judging from the comprehensive potential ecological risk index, the potential ecological risks of the heavy metals in the study area is minor in graded, but the heavy metals in the soil of the mixed sewage irrigation area and the industrial sewage irrigation area have a moderate grade of potential ecological risks at the depth of $50-80 \mathrm{~cm}$. Therefore, although the content of the heavy metals in the soil of the three kinds of sewage irrigation areas in the study area is safe, the potential ecological risk of $\mathrm{Cd}$ is quite high, which should be paid attention to.
\end{abstract}

\section{INTRODUCTION}

China is a large agricultural country, and irrigation water is essential for agricultural production, and the amount of irrigation water directly affects grain production. Because of the shortage of water resources and the aggravation of the situation of water pollution, competition for water between industry and agriculture is severe and the contradiction between supply and demand is prominent. However, with the development of economy, the water demand of industry is often met with by encroaching upon agricultural water consumption. Therefore, to ensure that farmland irrigation can be carried out normally, agriculture is forced to solve the problem of water demand through other ways. Sewage irrigation is one of the ways to solve the shortage of water in agriculture. The use of sewage irrigation not only improves the efficiency of water resources usage (Xin et al. 2011), relieves the pressure of water shortage in agriculture, but also can provide the nutrients needed for crop growth (Sheng et al. 2016). Rational use of sewage irrigation is an effective way to realize the utilization of sewage resources and reduce the discharge of sewage. However, most of the sewage for irrigation is not treated or the degree of treatment is not up to the standard of farmland water, which will cause the heavy metals, organics, toxic and harmful substances in the sewage to enter into the soil along with the irrigation, and eventually cause soil pollution when accumulated to a certain extent (Chen et al. 2012, Liu et al. 2017). The quality of the soil is closely related to agricultural production, human health and ecological security, but the soil suffers from the pollution and destruction caused by human production activities and becomes the final acceptor of most pollutants (Burges et al. 2015). Although the soil itself has a certain capacity of self-purification, when the concentration of the pollutants exceeds the carrying capacity of the soil, it will lead to the deterioration of the soil environment and adversely affect crops and agricultural products (Xu et al. 2018), thus endangering the health and safety of the humans. Using sewage for agricultural irrigation is a double-edged sword. How to use sewage irrigation reasonably and how to prevent and control 
soil environmental pollution have become soil environmental problems that need to be solved urgently at present (Wang et al. 2003). Taking the soil of the studied irrigation areas using sewage irrigation as the research objects, and the heavy metal content in the soil as the research goal, this paper evaluates and studies the pollution indicators, which is of great significance to the timely understanding and study of the soil pollution situation and the sustainable and healthy development of agriculture in the study area.

\section{MATERIALS AND METHODS}

Sample point settings: The study area is located in the North China Plain, which is an important grain producing area and an industrial city in China. With the development of the industry in the study area, the impact on the environment is becoming more and more obvious. The main sources of water in the study area are domestic sewage, mixed sewage and industrial sewage, and the irrigation areas irrigated by different water sources are divided into domestic sewage irrigation area, mixed sewage irrigation area and industrial sewage irrigation area, and 5 sampling points have been set at appropriate positions in each irrigation are.

Sample collection and preservation: In the irrigation areas irrigated with different types of sewage, the soil samples were taken according to the depth of 0-20, 20-50 and 50-80 $\mathrm{cm}, 5$ sampling points are set in each irrigation area respectively, and 5 soil samples of the same depth were mixed into one sample. The soils were naturally air-dried indoors, and the impurities were removed. They were later ground and screened with a $2 \mathrm{~mm}$ sieve and preserved for future use.

Determination of soil $\mathbf{p H}$ values: Soil $\mathrm{pH}$ was determined by a glass electrode $\mathrm{pH}$ meter.

Determination of $\mathbf{P b}, \mathrm{Cu}, \mathrm{Zn}$ and $\mathrm{Cd}$ in the soil: After the digestion of soil samples the content of each heavy metal was determined by atomic absorption spectrophotometry.

\section{RESULTS AND ANALYSIS}

pH values of the soil: The $\mathrm{pH}$ value of the soil is one of the important indicators of soil fertility, and it also directly affects the transformation of the heavy metals in the soil (Wan et al. 2015). $\mathrm{pH}$ value also reflects the degree of acidity or alkalinity of the soil. According to the range of $\mathrm{pH}$, the soil can be classified as strong acidity ( $\mathrm{pH}$ value $<4.5$ ), acidity ( $\mathrm{pH}$ value 4.5-5.5), slight acidity ( $\mathrm{pH}$ value 5.5-6.5), neutrality ( $\mathrm{pH}$ value $6.5-7.5$ ), slight alkalinity $(\mathrm{pH}$ value 7.5-8.5), alkalinity ( $\mathrm{pH}$ value $8.5-9.0$ ) and strong alkalinity $(\mathrm{pH}>9.0)$. The different acidity or alkalinity of the soil has different effects on the growth of crops, and only when $\mathrm{pH}$ value is within the suitable range, can the soil benefit the growth and development the crops and can the absorption and utilization of various nutrients from the soil reach the highest level. The $\mathrm{pH}$ values of the soil depth of $0-20 \mathrm{~cm}, 20-$ $50 \mathrm{~cm}$ and $50-80 \mathrm{~cm}$ in the irrigation areas of the three kinds of water quality were analyzed and presented in Fig. 1.

According to Fig. 1, it can be seen that (1) the $\mathrm{pH}$ values of the soil of the irrigation areas of different kinds of water quality all show an upward trend along with the increase of soil depth, but the $\mathrm{pH}$ values increase in each layer of the irrigation areas of different kinds of water quality are different. The $\mathrm{pH}$ value of the domestic sewage irrigation area increases by $0.60 \%$ from Layer $0-20 \mathrm{~cm}$ to Layer $20-50 \mathrm{~cm}$ and by $1.66 \%$ from $20-50 \mathrm{~cm}$ to $50-80 \mathrm{~cm}$; the $\mathrm{pH}$ value of the mixed sewage irrigation area increases by $2.43 \%$ from Layer $0-20 \mathrm{~cm}$ to Layer $20-50 \mathrm{~cm}$ and by $1.07 \%$ from $20-50 \mathrm{~cm}$ to $50-80 \mathrm{~cm}$, and. The $\mathrm{pH}$ value of the industrial sewage irrigation area increases by $1.05 \%$ from Layer $0-20 \mathrm{~cm}$ to Layer $20-50 \mathrm{~cm}$ and by $0.46 \%$ from $20-50 \mathrm{~cm}$ to $50-80 \mathrm{~cm}$; (2)

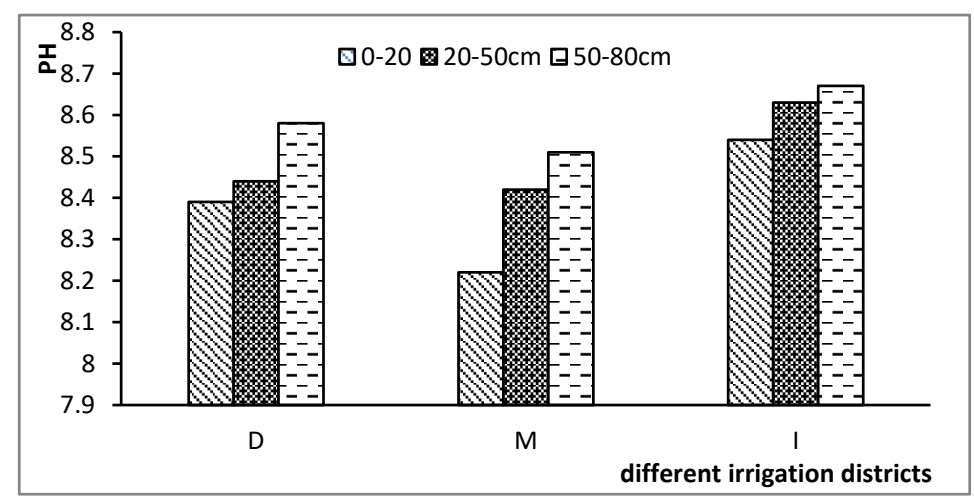

Note: D-domestic sewage irrigation area, M-mixed irrigation area, I-industrial sewage irrigation area

Fig. 1: $\mathrm{pH}$ value of soil at different depths in different irrigation areas. 
according to the criteria of $\mathrm{pH}$ classification of soil acidity and alkalinity, it can be seen that the average $\mathrm{pH}$ value of the domestic sewage irrigation area is 8.47 , the average $\mathrm{pH}$ value of the mixed sewage irrigation area is 8.38 , therefore the soil of the irrigation areas of these two kinds of water quality is slight alkalinity, and the average $\mathrm{pH}$ value of the industrial sewage irrigation area is 8.61 which is alkalinity.

Heavy metal content in the soil: Based on the screening values of "Soil Environmental Quality Risk Control Standard for Soil Contamination of Agricultural Land" (GB156182018), the environmental quality evaluation on the soil of the irrigation areas using three kinds of sewage in the study area was carried out. Since the $\mathrm{pH}$ values in this study area are all greater than 7.5 , when the soil $\mathrm{pH}>7.5$, the standard values of the evaluation indicators of $\mathrm{Pb}, \mathrm{Cu}, \mathrm{Zn}$ and $\mathrm{Cd}$ in the soil are $170 \mathrm{mg} / \mathrm{kg}, 100 \mathrm{mg} / \mathrm{kg}, 300 \mathrm{mg} / \mathrm{kg}$ and $0.6 \mathrm{mg} / \mathrm{kg}$, respectively.

The comprehensive assessment of the soil environmental pollution was carried out using the combination of single factor index method and Nemerow composite index method:

\section{Single Factor Index Method}

$$
I=\frac{C_{i}}{C_{0}}
$$

In this formula, $I$ is the single factor index of various evaluation indicators, $C_{I}$ is the measured value(s) of various evaluation indicators, and $C_{0}$ is the standard value(s) of various evaluation indicators.

\section{Nemerow Composite Index Method}

$$
\begin{gathered}
P I=\sqrt{\frac{\bar{I}^{2}+I 2_{\max }}{2}} \\
\bar{I}=\frac{1}{n} \sum_{i=1}^{n} I_{i}
\end{gathered}
$$

In the formula: $\bar{I}$ is the average value of the single factor indexes of the evaluation indicators; is the maximum value of the single factor indexes of various evaluation indicators; $P I$ is the comprehensive pollution index, and; $n$ is the quantity of the indicators.

The evaluation criteria for the degrees of soil pollution using single factor index method and comprehensive index method are given in Table 1 (Liu et al. 2015).

The soil of different kinds of water quality is evaluated based on the measured values and standard values of various heavy metals and using single factor index and comprehensive index respectively, and the evaluation results are given in Table 2.

Table 1: Evaluation and grading criteria for heavy metal pollution in the soil.

\begin{tabular}{|c|c|c|c|c|c|c|c|c|}
\hline \multirow[t]{2}{*}{ Soil depth } & \multirow[t]{2}{*}{ Sampling point } & \multicolumn{4}{|l|}{$\mathrm{I}_{\mathrm{i}}$} & \multirow[t]{2}{*}{$\bar{I}$} & \multirow[t]{2}{*}{$I_{\max }$} & \multirow[t]{2}{*}{ PI } \\
\hline & & $\mathrm{Pb}$ & $\mathrm{Cu}$ & $\mathrm{Zn}$ & $\mathrm{Cd}$ & & & \\
\hline \multirow[t]{3}{*}{$0-20 \mathrm{~cm}$} & $\mathrm{D}_{1}$ & 0.433 & 0.233 & 0.118 & 0.450 & 0.308 & 0.450 & 0.386 \\
\hline & $\mathrm{M}_{1}$ & 0.529 & 0.286 & 0.167 & 0.500 & 0.371 & 0.529 & 0.457 \\
\hline & $\mathrm{I}_{1}$ & 0.514 & 0.253 & 0.131 & 0.517 & 0.354 & 0.517 & 0.443 \\
\hline \multirow[t]{3}{*}{$20-50 \mathrm{~cm}$} & $\mathrm{D}_{2}$ & 0.478 & 0.185 & 0.102 & 0.447 & 0.304 & 0.478 & 0.401 \\
\hline & $\mathrm{M}_{2}$ & 0.452 & 0.233 & 0.134 & 0.512 & 0.333 & 0.512 & 0.432 \\
\hline & $\mathrm{I}_{2}$ & 0.422 & 0.218 & 0.118 & 0.617 & 0.344 & 0.617 & 0.499 \\
\hline \multirow[t]{3}{*}{$50-80 \mathrm{~cm}$} & $\mathrm{D}_{3}$ & 0.313 & 0.176 & 0.096 & 0.400 & 0.246 & 0.400 & 0.332 \\
\hline & $\mathrm{M}_{3}$ & 0.457 & 0.248 & 0.139 & 0.700 & 0.386 & 0.700 & 0.565 \\
\hline & $\mathrm{I}_{3}$ & 0.564 & 0.291 & 0.156 & 0.633 & 0.411 & 0.633 & 0.534 \\
\hline
\end{tabular}

\begin{tabular}{|lllll|}
\hline \multirow{2}{*}{ Grade } & \multicolumn{2}{l}{ Single Factor Pollution Index } & \multicolumn{2}{l|}{ Comprehensive Pollution Index } \\
\cline { 2 - 5 } & Pollution Index & Pollution Grade & Pollution Index & Pollution Grade \\
\hline I & $\mathrm{I}<1$ & Cleanness & PI $\leq 0.7$ & Safety \\
II & $1 \leq \mathrm{I}<2$ & Minor Pollution & $0.7<\mathrm{PI} \leq 1$ & Alert \\
III & $2 \leq \mathrm{I}<3$ & Mild Pollution & $1<\mathrm{PI} \leq 2$ & Mild Pollution \\
IV & $3 \leq \mathrm{I}<5$ & Moderate Pollution & $2<\mathrm{PI} \leq 3$ & Moderate Pollution \\
V & $\mathrm{I} \geq 5$ & Severe Pollution & PI $>3$ & Severe Pollution \\
\hline
\end{tabular}

Table 2: Results of soil environmental quality evaluation. 
The degrees of soil pollution of different kinds of water quality were determined by comparing the results of soil environmental quality evaluation with the evaluation and grading criteria of heavy metal pollution in the soil.

It can be seen from Table 1 and Table 2 that: (1) all values of $I_{i}$, which are the single factor pollution index values of various heavy metal elements in the irrigation areas with different kinds of water quality at different soil depth are less than 1 , indicating that the soil is clean and not contaminated by heavy metals; (2) the single factor pollution indexes of various heavy metal elements at different soil depths: the sequence of single factor pollution indexes of the soil at the depth of $20-50 \mathrm{~cm}$ in the domestic sewage irrigation area at the $0-20 \mathrm{~cm}$ layer of the mixed sewage irrigation area is $\mathrm{Pb}>\mathrm{Cd}>\mathrm{Cu}>\mathrm{Zn}$, and the sequence of the single factor pollution indexes of the soil at rest different depths is $\mathrm{Cd}>\mathrm{Pb}>\mathrm{Cu}>\mathrm{Zn}$; (3) the regular patterns of the variation of the heavy metal elements at different depths of the soil in different kinds of water quality are: the variation patterns of $\mathrm{Pb}, \mathrm{Cu}$ and $\mathrm{Zn}$ in the mixed sewage irrigation area and in the industrial sewage irrigation area are both $0-20 \mathrm{~cm}>20-50 \mathrm{~cm}$ $<50-80 \mathrm{~cm}$; the variation pattern of $\mathrm{Cd}$ is $0-20 \mathrm{~cm}<20-50 \mathrm{~cm}$ $>50-80 \mathrm{~cm}$; the variation pattern of $\mathrm{Cu}, \mathrm{Zn}$ and $\mathrm{Cd}$ in domestic sewage irrigation area is $0-20 \mathrm{~cm}>20-50 \mathrm{~cm}>50-80 \mathrm{~cm}$; and the variation pattern of $\mathrm{Pb}$ is $0-20 \mathrm{~cm}<20-50 \mathrm{~cm}>50-80 \mathrm{~cm}$; (4) the sequence of the comprehensive pollution indexes of the $0-20 \mathrm{~cm}$ is: mixed sewage irrigation area $>$ industrial sewage irrigation area $>$ domestic sewage irrigation area, the sequence of the comprehensive pollution indexes of the $20-50 \mathrm{~cm}$ is: industrial sewage irrigation area $>$ mixed sewage irrigation area $>$ domestic sewage irrigation area, and the sequence of the comprehensive pollution indexes of the $50-80 \mathrm{~cm}$ is: mixed sewage irrigation area $>$ industrial sewage irrigation area $>$ domestic sewage irrigation area; and (5) the values of $P I$, which are the comprehensive pollution indexes of various heavy metals in irrigation areas with different kinds of water quality at different soil depth, are all less than 0.7 , indicating that the soil pollution grade belongs to the safety level.

According to the evaluation results of the single factor index method and the comprehensive index method, none of the soils in the irrigation areas of different kinds of water quality in the study area is polluted by heavy metals, which accords with the national soil environmental quality requirements, therefore the soils can be used for the clean production of crops.

Potential ecological risk assessment of heavy metal content in the soil: Because the amount of the exposure to pollutants in the environment to various extents has an impact on human health, when the risks of the pollutants are being assessed, multiple factors such as the pollutant content and toxicology are taken into overall consideration, therefore with the development of ecological risk assessment, models for the evaluation methods appear. The widely adopted method in assessing the ecological risks of heavy metals in the soil is the potential ecological risk index presented by Hakanson in 1980. This method closely correlates the effects of heavy metals on the ecology and the effects on the environment with the toxicological properties of the heavy metals while taking into consideration the content of heavy metals in the environment to quantitatively analyze the scale of potential risks of heavy metals in the soil, which is of great significance to the ecological risk assessment of heavy metals in the soil.

The calculation formula of the Hakanson potential ecological risk index is (He 2018):

$$
\begin{gathered}
P_{i}=C_{i} / B_{i} \\
E_{i}=T_{i} / P_{i} \\
R I=\sum_{i=1}^{n} E_{i}
\end{gathered}
$$

In the formula, $C_{i}$ is the measured value of the content of heavy metal $i$ in the soil; $B_{i}$ is the calculated background value of heavy metal $i$ in the soil; $P_{i}$ is the pollution coefficient of heavy metal $i$ in the soil; $T_{i}$ is the toxicity coefficient of one single pollutant; $E_{i}$ is potential ecological risk coefficient of heavy metal $i$ in the soil; $R I$ is potential ecological risk index of multiple heavy metals in the soil.

Hakanson potential ecological risk index method is adopted to specifically grade and assess the ecological risks of the heavy metals. The background values and toxicity coefficients of the heavy metals in the study area are given in Table 3, and the correlation between the potential ecological risk index and the pollution levels are presented in Table 4.

Based on the potential ecological risk index method, the $E_{i}$ and $R I$ of various heavy metals in the study area were calculated and given in Table 5.

Table 3: Background values and toxicity coefficients of the heavy metals.

\begin{tabular}{|lllll|}
\hline Sampling point & $\mathrm{Pb}$ & $\mathrm{Cu}$ & $\mathrm{Zn}$ & $\mathrm{Cd}$ \\
\hline$T_{i}$ & 5 & 5 & 1 & 30 \\
$B_{i}$ & 21.5 & 21.8 & 78.4 & 0.094 \\
\hline
\end{tabular}

Table 4: Correlation between the potential ecological risk index and pollution levels.

\begin{tabular}{|lll|}
\hline$E_{i}$ & $R I$ & Risk Grade \\
\hline$<40$ & $<150$ & Minor \\
$40 E_{i}<80$ & $150 R I<300$ & Moderate \\
$80 E_{i}<160$ & $300 R I<600$ & Strong \\
$160 E_{i}<320$ & $6000 R I$ & Very Strong \\
$320 E_{i}$ & & Extremely Strong \\
\hline
\end{tabular}


Table 5: Potential ecological risk index of the heavy metals in the soil $E_{i}$ and $R I$.

\begin{tabular}{|lllllll|}
\hline \multirow{2}{*}{ Soil depth } & Sampling point & \multicolumn{2}{l}{$E_{i}$} & & & \multirow{2}{*}{$R I$} \\
\cline { 2 - 5 } & & $\mathrm{Pb}$ & $\mathrm{Cu}$ & $\mathrm{Zn}$ & $\mathrm{Cd}$ & \\
\hline 0-20cm & $\mathrm{D}_{1}$ & 17.13 & 5.34 & 0.45 & 86.17 & 109.09 \\
& $\mathrm{M}_{1}$ & 20.93 & 6.55 & 0.64 & 95.74 & 123.87 \\
& $\mathrm{I}_{1}$ & 20.33 & 5.80 & 0.50 & 98.94 & 125.57 \\
& $\mathrm{D}_{2}$ & 18.92 & 4.23 & 0.39 & 85.53 & 109.07 \\
& $\mathrm{M}_{2}$ & 17.86 & 5.35 & 0.51 & 97.98 & 121.70 \\
& $\mathrm{I}_{2}$ & 16.67 & 5.01 & 0.45 & 118.09 & 140.21 \\
& $\mathrm{D}_{3}$ & 12.38 & 4.04 & 0.37 & 76.60 & 93.39 \\
& $\mathrm{M}_{3}$ & 18.08 & 5.69 & 0.53 & 134.04 & 158.35 \\
Min & $\mathrm{I}_{3}$ & 22.30 & 6.66 & 0.60 & 121.28 & 150.83 \\
Max & & 12.38 & 4.04 & 0.37 & 76.60 & 93.39 \\
Mean & & 22.30 & 6.66 & 0.64 & 134.04 & 158.35 \\
& & 18.29 & 5.41 & 0.49 & 101.60 & 125.79 \\
\hline
\end{tabular}

According to Table 4 and Table 5, it can be seen that: (1) the values of $E_{i}$ which are the ecological risk indexes of $\mathrm{Pb}, \mathrm{Cu}$ and $\mathrm{Zn}$ in the soil at different depth and irrigated with different kinds of water quality, are all less than 40, and the ecological risk grade of the soil is minor. For $\mathrm{Cd}$, except that the ecological risk coefficient of the domestic sewage irrigation area with the depth of $50-80 \mathrm{~cm}$ is 76.6 , which belongs to the moderate risk grade, the ecological risk coefficients of the rest of the soil in the irrigation areas with different kinds of water quality at different depth are within the range of $80 \quad E_{i}<160$, and the ecological risk grades belong to the strong grades; (2) judging from the mean values of the soil at different depths, the ecological risk coefficient of $\mathrm{Pb}$ decreases with the increase of the soil depth; the variation pattern of the ecological risk coefficient of $\mathrm{Cu}$ and $\mathrm{Zn}$ is $0-20 \mathrm{~cm}>50-80 \mathrm{~cm}>20-50 \mathrm{~cm}$; and the variation pattern of ecological risk coefficient of $\mathrm{Cd}$ increases with the increase of the soil depth; (3) the sequence of the average ecological risk indexes of various heavy metal elements in a descending manner is $\mathrm{Cd}(101.60)>\mathrm{Pb}(18.29)>\mathrm{Cu}$ (5.41) $>\mathrm{Zn}$ (0.49). The ecological risk index of $\mathrm{Cd}$ is the highest in the soil of the study area, indicating that $\mathrm{Cd}$ in the soil has strong potential ecological risks, and the potential ecological risks of other heavy metal elements are quite low; (4) judging from the comprehensive ecological risk index, the ecological risk coefficients of the soil of $0-20 \mathrm{~cm}$ and $20-50 \mathrm{~cm}$ irrigated with different kinds of water quality are all less than 150, therefore the ecological risk grade is minor. The comprehensive ecological risk index of the soil of $50-80 \mathrm{~cm}$ in the domestic sewage irrigation area is 93.39 , which is less than 150, therefore the ecological risk grade is minor; the comprehensive ecological risk coefficients of the soil in the mixed sewage irrigation area and industrial sewage irrigation area are 158.35 and 150.83 respectively, which are both higher than 150 , therefore the ecological risk grade is moderate; (5) judging from the comprehensive risk indexes of different soil depths, the average values of the comprehensive ecological risk indexes of the soil in the irrigation areas with three different kinds of water quality with the depth of $0-20 \mathrm{~cm}, 20-50 \mathrm{~cm}$ and $50-80 \mathrm{~cm}$ are, respectively, 119.51, 123.66 and 134.19 , the overall average value of the comprehensive ecological risk indexes is 125.97 , and the average values of all ecological risk indexes are all less than 150, therefore evaluated from the perspective of mean values, the comprehensive ecological risk grade of the study area is minor.

\section{CONCLUSION}

Sewage irrigation can alleviate the shortage of agricultural water, but the long-term use of sewage irrigation will cause the continuous accumulation of metals in the soil and lead to soil pollution. Heavy metal pollution in the soil will restrict the sustainable development of local agriculture and adversely affect the ecological environment and the quality of agricultural products, and then affect human health. This paper takes the irrigation areas which have been using sewage irrigation for many years as the research objects and evaluates the heavy metals in the soil in the study area to understand the pollution status and the potential ecological risks of heavy metals in the soil in the study area, as it is of great significance in ensuring the quality and safety of agricultural products and human health. The main conclusions are as follows: (1) judging from the $\mathrm{pH}$ values of the soil in the irrigation areas with different kinds of water quality at different depth in the study area, the soil in the study area is slightly alkaline 
or alkaline. Risk control standards for the content of heavy metals in the soil are different as the acidity or alkalinity of the soil is different; (2) the status of heavy metal pollution in the soil is evaluated using single factor index method and Nemerow comprehensive index method. The contents of heavy metals $\mathrm{Pb}, \mathrm{Cu}, \mathrm{Zn}$ and $\mathrm{Cd}$ in the soil all belong to the safety grade, and the soil is not contaminated; (3) regarding the potential ecological risks in the soil, the heavy metals $\mathrm{Pb}, \mathrm{Cu}$ and $\mathrm{Zn}$ show minor ecological risks judging from the single indexes, while Cd shows strong ecological risks; judging from the comprehensive index, the overall potential ecological risks of the heavy metals in the soil of the study area belong to the minor grade, but the potential ecological risks of the heavy metals in the mixed sewage irrigation area and in the industrial sewage irrigation area belong to moderate grade at the depth of $50-80 \mathrm{~cm}$; (4) although the content of heavy metals in the soil does not exceed the standards, and still belongs to the safety grade, and judging from the comprehensive potential ecological risks, the potential ecological risks in the study area is not serious, the potential ecological risk grade of heavy metal $\mathrm{Cd}$ in the soil is quite high, and the comprehensive ecological risk grade of the soil in the mixed sewage irrigation area and the industrial sewage irrigation area at the depth of $50-80 \mathrm{~cm}$ is moderate. Therefore, the potential ecological risks of $\mathrm{Cd}$, $50-80 \mathrm{~cm}$ in the soil of the mixed sewage irrigation area and the industrial sewage irrigation area in the study area should be paid great attention to.

\section{REFERENCES}

Burges, A., Epelde, L. and Garbisu, C. 2015 Impact of repeated singlemetal and multi-metal pollution events on soil quality. Chemosphere. 120: 8-15.

Chen, T., Chang, Q.R., Liu, J., Liu, Z. and Liu, H.F.2012. Pollution and potential environment risk assessment of soil heavy metals in sewage irrigation area. Journal of Agro-Environment Science, 31(11): 21522159.

He, X. 2018. Ecological risk assessment and health risk assessment of soil heavy metals in Xi' an original irrigation area. Northwest University, 21-23.

Liu, X.Y., Liang, Q., Gao, R.T., Zhang, H., Wang, L.J. and Zhou, S. X. 2015. Environmental risk assessment of soil heavy metal pollution of farmlands with long period of sewage irrigation. Journal of Ecology and Rural Environment, 31(4): 572-578.

Liu, Y.P., Liu, H.Y., Wu, L., Xu, M., Cui, J.L., Gao, W.Y., Cheng, C. and Yu, X.H. 2017. Co-contamination of heavy metals and antibiotics in soils under husbandry wastewater irrigation in Guiyang City. Acta Scientiae Circumstantiae, 37( 3): 1074-1082.

Sheng, F., Wu, D. and Zhang, L.Y. 2016. Review on effect of reclaimed water irrigation on soil water movement in cropland. Transactions of the Chinese Society of Agricultural Engineering. 32(Supp. 2): 46-51.

Wan, L., Zhang, M.Y., Lu, S. and Hu, K. 2015. Study progress on effect of polluted water irrigation on soil and problem analysis. Ecology and Environmental Sciences, 24(5): 906-910.

Wang, G.L. and Lin, W.J. 2003. Contamination of soil from sewage irrigation and its remediation. Journal of Agro-Environment Science, 22(2): 163-166.

Xin, S.Z., Li, H.F. and Su, D.C. 2011. Concentration characteristics and historical changes of heavy metals in irrigation sewage in China. Journal of Agro-Environment Science, 30(11): 2271-2278.

Xu, J.M., Meng, J., Liu, X.M., Shi, J.C. and Tang, X.J. 2018.Control of heavy metal pollution in farmland of China in terms of food security. Bulletin of Chinese Academy of Sciences, 33(2): 153-159. 